\title{
Studies on jute fiber/polypropylene, jute fiber/Polylactide and glass fiber/Polypropylene composites for automotive application
}

\author{
Rui-Hua Hu${ }^{1, a}$, Kui-Hua Hü,b, Guo-Hua Yang ${ }^{3}$ \\ ${ }^{1}$ Zhengzhou University of Industrial Technology, Zhengzhou 451150, China \\ ${ }^{2}$ CAMA(Luoyang) Electronics Co., Ltd., Luoyang, China \\ ${ }^{3}$ Ya Bang Auto-Accessory Co. Ltd., Luoyang, Henan Province, China \\ âRuihuahu926@hotmail.com; 'bukh@cama-e.com
}

\begin{abstract}
Keywords: Green material, Natural fiber, Glass fiber, Composite material, Mechanical property
Abstract. In the past few years, the awareness of environment protection all over the world and the release of strict guideline and regulations concerning automotive end-of-life requirement forced the automakers to seek eco-friendly materials to make car "greener". In this work, three composites are fabricated. One is traditionally used glass fiber reinforced composite. The others are green materials: jute fiber reinforced polypropylene and jute fiber reinforced polylactide. The manufacturing procedures are developed and the properties of these materials are tested and compared with glass fiber/polypropylene composite.
\end{abstract}

\section{Introduction}

Traditionally, automotive industry largely uses glass fiber reinforced polymeric composites to make structural components for purpose of weight reduction. However, glass-reinforced plastics still exhibit shortcomings such as their relatively high fiber density, difficulty to machine, and poor recycling properties, particularly the potential health hazards posed by glass-fiber particles[1,2].

Moreover, the disposal of the waste glass fiber reinforced polymeric composites is a serious problem. The most common and economic route to treat waste car interior are incineration and landfill. In combined heat and power plants, the heat from incineration is used to create electricity, as well as feed a district heating system. However, $60 \%$ of the scrap is left behind as ash after incineration. Due to the presence of inorganic loads in composites, this ash may be a pollutant, and is, depending on the type and post-treatment options, either dumped at a landfill or recycled as a substitute construction material. The inorganic loads also lead to the emission of hazardous flue gasses in that the small glass fiber spares may cause problems to the flue gas cleaning steps, mainly at the dust filter devices.

The awareness of environment protection all over the world and the release of strict guideline and regulation in European and some Asian countries concerning automotive end-of-life requirement forced the automakers to seek eco-friendly materials to make car "greener" [1]. Therefore, in the past few years, natural fibers have been used as reinforcement in composite components. The advantages of natural fiber are low cost, low density, renewability, high strength and modulus of elasticity and low heat conductivity. These make it very suitable for automotive components, especially for interior components[3,4].

Natural fiber as reinforcement in polymer to make eco-friendly composites is a very ideal substitution for automobile interior. Such composites are degradable materials. In recent years, aiming at automotive applications, a lot of work has been performed to fabricate natural fiber reinforced composites.

Natural fiber reinforced polypropylene(PP) is more advantageous than glass fiber reinforced PP, because this material is fully combustible when it is treated by incineration. Also, it overcomes the disadvantages of glass fiber, such as hazardous debris when machined. However, polypropylene is not a biodegradable polymer.

To further make a fully biodegradable composite, polylactide (PLA) is used and combined with natural fiber in this research. Polylactide is a degradable polymer which is called "green plastic for the 21st century" [5], not only because it is degradable but that it is synthesized from renewable resources 
as well, such as corn or potatoes. It attracted much attention in recent years for the reasons that it offers an alternative to maintaining sustainable development of economically and ecologically technology leading to the reduction of fossil-based raw materials, complete biological degradability, the reduction in the volume of garbage and compost ability in the natural cycle, protection of the climate through the reduction of carbon dioxide released, as well as the application possibilities of agriculture resources for the production of green materials.

PLA can be totally degraded in aerobic or anaerobic environments in two months to five years, and chain fragmentation can be obtained at higher humidity and temperature as soon as 7 days [6]. Due to its degradability when exposed to heat and humidity, nowadays, polylactide is mainly used for packaging applications such as food packaging for short shelf life products, containers, drinking cups, salad cups, overwrap and lamination films, and blister packages.

The authors of this article fabricated and investigated glass fiber reinforced polypropylene, jute fiber reinforced polypropylene, and jute fiber reinforced polylactide by special procedures. The properties of these materials are tested. The applicability of these materials for car interior is also discussed.

\section{Materials}

Polylactide(PLA) fiber (3D/38F) was purchased from Shenzhen BrightChina Industrial Co., Ltd.. The density of the PLA fiber is $1.24 \mathrm{~g} / \mathrm{cm}^{3}$. The melting index at $190^{\circ} \mathrm{C}$ is $10-15 \mathrm{~g} / 10 \mathrm{~min}$. The yielding strength is $54 \mathrm{MPa}$. The fiber length is around $80 \mathrm{~mm}$. The morphology of PLA fiber is shown in Fig.1(a).

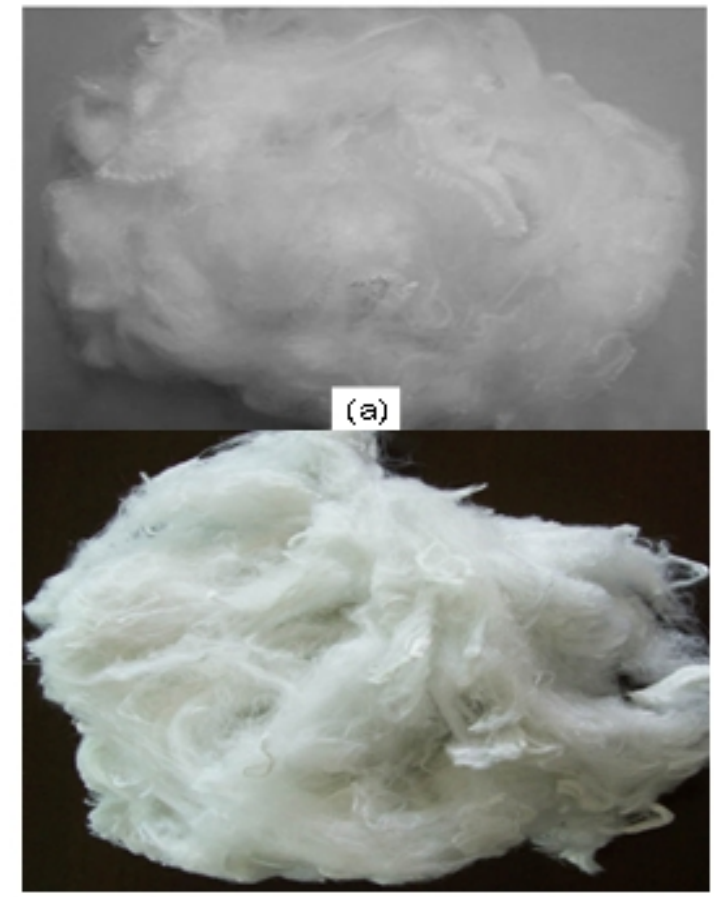

(c)

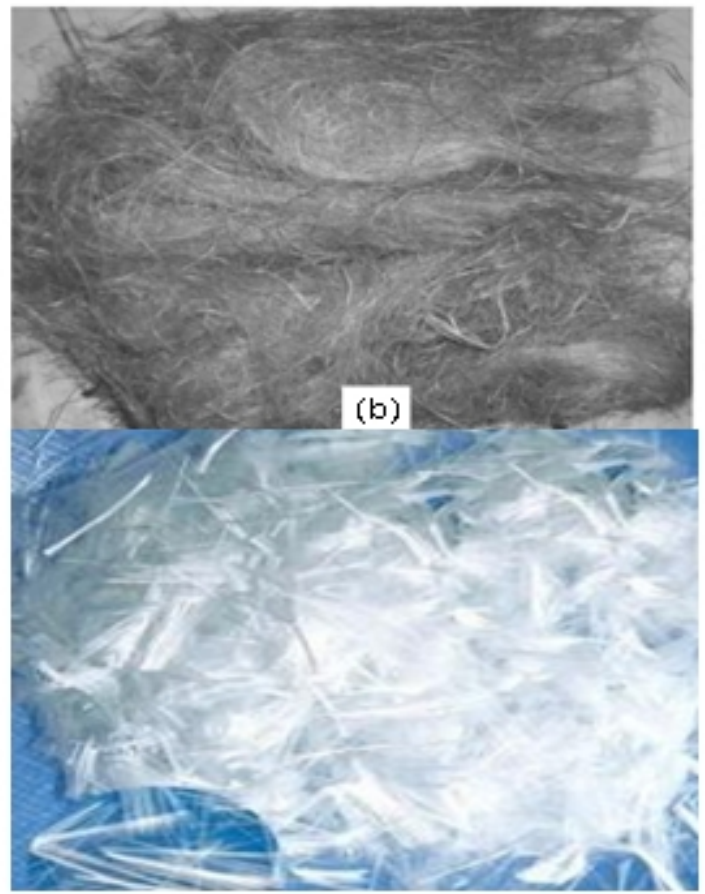

(d)

Figure1. Morphology of polylactide fiber (a), (b) China jute fiber

(c) Polypropylene fiber, (d) Glass fiber

China jute fiber was used as reinforcement in composite. China jute (Abutilon theophrasti Medic) is a regional grown fiber plant. It is a preponderant renewable resource in China. The fiber, removed from jute stem by retting, with original length of $2.5-4 \mathrm{~m}$, was cut into short fibers of $100 \mathrm{~mm}$. The density of the fiber was tested to be $0.94 \mathrm{~g} / \mathrm{cm}^{3}$. The morphology of jute fiber is shown in Fig. 1(b).

Short polypropylene fiber(PP), with the length of $100 \mathrm{~mm}$, was purchased from Luoyang Petro-chemical Co. Ltd.. The size of $\mathrm{PP}$ is $4 \mathrm{D} / 102 \mathrm{~F}$, with a melting point $176^{\circ} \mathrm{C}$, and density $0.91 \mathrm{~g} /$ $\mathrm{cm}^{3}$. The tensile strength is above $320 \mathrm{MPa}$. 
Glass fiber(alkali free) was received from Hentai fiber plant, with the length $100 \mathrm{~mm}$, and diameter $10 \mu \mathrm{m}$. The tensile strength is above $2000 \mathrm{MPa}$.

Morphology of polypropylene fiber and glass fiber are shown in Fig.1(c) and (d).

\section{Experimental results and discussion}

The following composites were manufactured: glass fiber/PP; jute fiber/PP; jute fiber/PLA.

The fabrication process includes two main steps: making felt and pressed molding. They are described as follows.

Fibers of polymer(PP or PLA) and reinforcement fiber( glass fiber or jute fiber respectively) were weighed according to the fractions in the expected composites. In this research, the weight to weight ratio of polymeric fiber and reinforcement fiber is 4:6, respectively. Then two kinds of fibers were mixed and fed into a fiber opening machine to be further mixed. And then a combing process was followed by putting the mixture into a carding machine. The next step was cross lapping of the combed fiber mixture. The mixture of fibers was needle punctured to make felt.

Felt of fiber mixture was cut according to the product shape and size. The felt was placed onto a heating machine panel for $5 \mathrm{~min}$ at $180^{\circ} \mathrm{C}$ (for PLA fiber) and $170^{\circ} \mathrm{C}$ ( for PP fiber) respectively. Then the hot felt was quickly moved to a mold on a cold press machine. After $5 \mathrm{~min}$ pressing at $0.45 \mathrm{MPa}$, the product was removed from the mold. The detail process is shown in Fig.2.

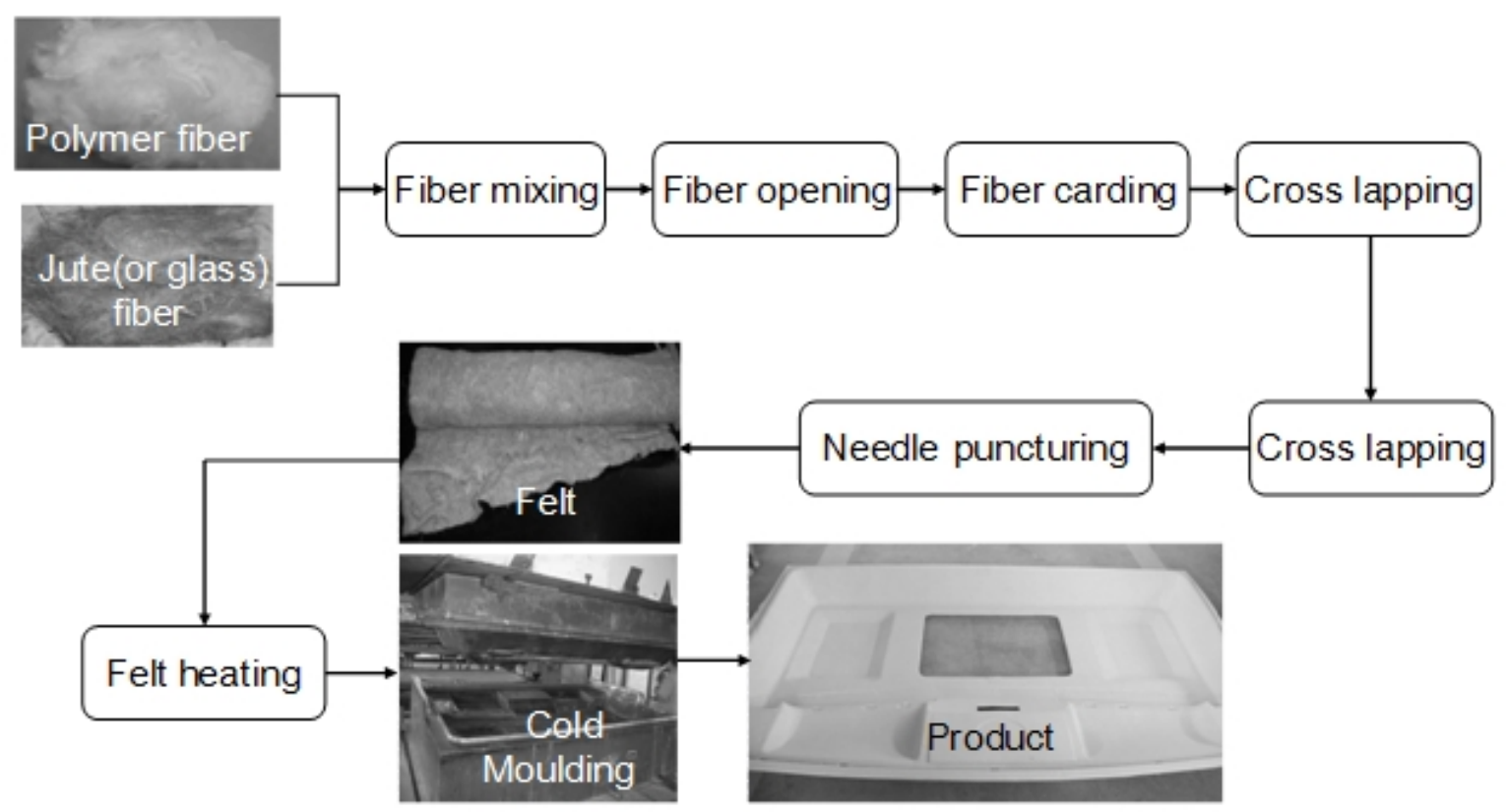

Figure 2. Manufacturing processes of glass fiber/PP, jute fiber/PP and jute fiber/PLA

Tensile strength of the composites was tested(following ASTM D3039). Tensile test samples were cut from a composite plate, as shown in Fig.3(a). The size of the sample is $300 \mathrm{X} 30 \mathrm{~mm}$. At least 5 samples were tested and the testing results were averaged as the tensile strength. Tests were conducted on a universal testing machine with a cross head speed $1 \mathrm{~mm} / \mathrm{min}$. The test setup is shown in Fig.3(b).

After the composites were finished, the structure of the composite was inspected and compared. Three composites have loose and porous microstructures. Such structure is favorable to maintain the flexiblity of the composites and fit the shape of the car compartment and thus make them easy to install into car. The detail morphology of the jute/pp is shown in Fig.4.

The thickness was measured. The average thickness of each composite is listed in Table 1. Glass fiber/pp composite has the largest thickness, $8.18 \mathrm{~mm}$. The thickness of jute/PP is near to that of jute/PLA. The difference of thickness is resulted from the difference of stiffness of the fiber. Because the glass fiber is much stiffer to resist the pressure when composite is molded. 
The tensile test results are shown in table 1 . Compared with traditionally used glass/PP, the strength of jute/PP and jute/PLA composites shows a little higher tensile strength.

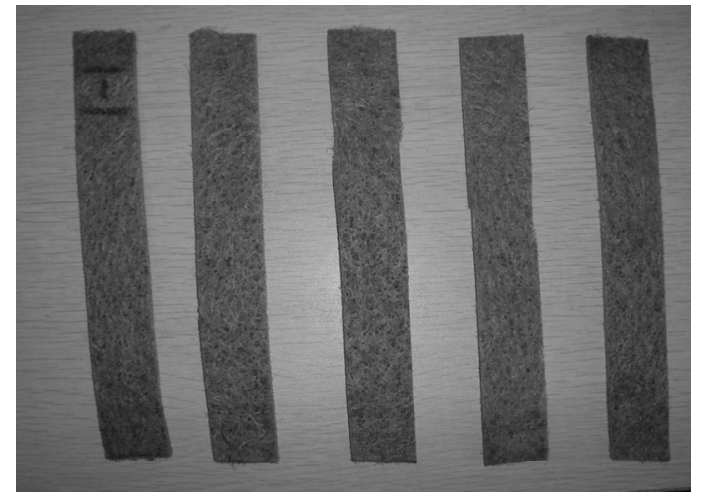

(a)

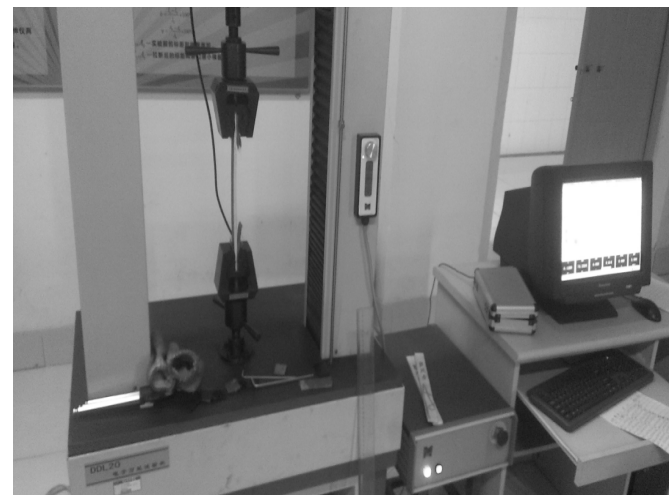

(b)

Figure 3. (a) Testing Sample; (b) Testing setup

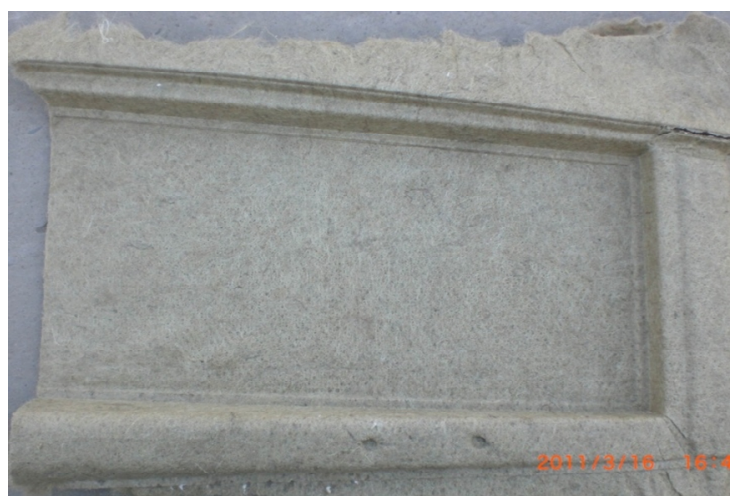

Figure 4. Morphology of jute/pp composite

Table. 1 Test results of Composite properties

\begin{tabular}{lccc}
\hline Material & Jute/PP & Jute/PLA & Glass fiber/PP \\
\hline $\begin{array}{l}\text { Fiber/Polymer } \\
\text { (weight/weight) }\end{array}$ & $6: 4$ & $6: 4$ & $6: 4$ \\
$\begin{array}{l}\text { Thickness (mm) } \\
\text { (Averaged) }\end{array}$ & 5.76 & 4.1 & 8.18 \\
Tensile strength (MPa) & $2.88 \pm 0.36$ & $3.73 \pm 0.46$ & $2.33 \pm 0.20$ \\
\hline
\end{tabular}

\section{Conclusions}

Green composites of natural jute fiber reinforced polypropylene and fully degradable jute fiber reinforced polylactide are fabricated. The fabrication process of jute fiber/PP is same as that of glass fiber/PP, which is traditionally used. The composite of jute fiber/PLA can be also obtained by only changing the heating temperature $170^{\circ} \mathrm{C}$ to $180^{\circ} \mathrm{C}$. The appearance and microstructures of three materials are very similar. They all have loose and porous microstructures. The microstructure makes the materials very flexible, thus the materials are easy to install into the car compartment. The tensile 
strength of jute strength of jute/PP and jute/PLA is a little higher than traditionally used glass/PP. It is concluded that the jute/PP and jute/PLA can totally substitute glass/PP as car interior.

\section{References}

[1] L. Amelia and D.A.Wahab: J. Cleaner Prod., Vol.17(2009), p1572.

[2] R. H. Hu and J. K. Lim: J. Comp. Mater., Vol.41(2007), p1655.

[3] G. Marsh: Mater. Today, Vol.4(2003), p36.

[4] A. Ashori: Vol. 99(2008), p4661.

[5] S. S. Ray, and M. Bousmina: Prog. Mater. Sci., Vol.50(2005), p962.

[6] R.H. Hu, M. Y. Sun and J. K. Lim: Mater. Des., Vol.31(2010), p3167. 